\title{
HIDROGÊNIO UMA FONTE DE ENERGIA PARA O FUTURO ${ }^{1}$
}

Ana Claudia $\mathrm{Cabral}^{2}$, Elisandro Pires Frigo ${ }^{3}$, Samara Moreira Perissato $^{4}$, Késia Damaris de Azevedo $^{5}$, Jianice Pires Frigo ${ }^{6}$, Gabriela Bonassa ${ }^{7}$

\footnotetext{
${ }^{1}$ Aceito para publicação em $2^{\circ}$ trimestre de 2014

${ }^{2}$ Universidade Estadual do Oeste do Paraná - UNIOESTE, PPGEA - Programa de Pós Graduação em Energia na Agricultura - Nível Mestrado, Cascavel-PR, Brasil, ea.anaclaudia@ gmail.com

${ }^{3}$ Prof. Dr. Adjunto da Universidade Federal do Paraná UFPR, Palotina - PR, Brasil, epfrigo@ gmail.com

${ }^{4}$ Acadêmica em Agronomia pela Universidade Federal do Paraná, Setor Palotina-PR, Brasil, samaraperissato@gmail.com

${ }^{5}$ Graduada em Tecnologia em Biotecnologia na Universidade Federal do Paraná, Palotina-PR, Brasil, kesia.damaris@gmail.com

${ }^{6}$ Acadêmica em Agronomia pela Universidade Regional Integrada do Alto Uruguai e das Missões - URI Campos de Santiago - RS, Brasil, jifrigo@yahoo.com.br

${ }^{7}$ Acadêmica em Tecnologia em Biocombustíveis pela Universidade Federal do Paraná UFPR- Setor Palotina/PR, Brasil;
}

\section{Resumo}

Este trabalho teve por objetivo analisar a geração energética do hidrogênio que é representado pelo símbolo $\mathrm{H}$ na tabela de elementos químicos, possibilitando analisar as recentes produções. Este elemento é um gás que quando entra em contato com o oxigênio, forma água sendo inflamável. A análise da literatura técnico-científica permitiu verificar que o hidrogênio é uma descoberta recente e promete muito para o futuro próximo a 2030, pois ainda devem-se desenvolver pesquisas voltadas para o armazenamento do hidrogênio para assim fortalecer o próprio.

Palavras-Chave: Elemento, Hidrogênio, Armazenamento.

\section{HYDROGEN AN ENERGY SOURCE FOR THE FUTURE ${ }^{1}$}

\section{Abstract}


This study aimed to analyze the generation of hydrogen energy is represented by the symbol $\mathrm{H}$ in the table of chemical elements, enabling the analysis of the recent productions, this element is a gas when it comes into contact with oxygen, so water is flammable. The analysis of the technical and scientific literature has shown that hydrogen is a recent discovery, and promises much for the future to 2030, they still must develop research focused on hydrogen storage so as to strengthen itself.

Keyword: Element, Hydrogen, Storage.

\section{Introdução}

Nos dias atuais a questão ambiental está em foco, buscando novas alternativas como fonte de energia e obtendo novos investimentos em pesquisas, isso é possível devido ao anseio tecnológico, porém o hidrogênio ainda é pobre se tratando da questão tecnológica energética do Brasil.

O hidrogênio encontra-se na tabela periódica dos elementos, apresentando elétrons residindo na sétima camada, pois este elemento se encontra na sétima camada no grupo $1^{\text {a }}$ metais alcalinos, sendo conhecido como o elemento menos denso, geralmente sua forma molecular, se encontra em formato de gás, o mesmo é inflamável, incolor, inodoro e insolúvel a água (MACEDO EL CARVALHO, 2006).

O hidrogênio pode ser encontrado através de eletrólise, reações de metais com ácidos, reações de carvão ou hidrocarbonetos com vapor de água a alta temperatura.

O presente trabalho tem o objetivo de revisar as informações sobre esta fonte de energia, servindo assim para a geração atual e facilitando os posteriores estudos sobre hidrogênio.

\section{Formas de armazenamento do hidrogênio}

Para os cientistas a problemática do hidrogênio é como gerar o gás e de que maneira armazenar em seguida vem a questão da infraestrutura do ambiente e a segurança do mesmo. O hidrogênio em estado líquido necessita ser armazenado em temperaturas a $-253^{\circ}$, ou seja, em baixa temperatura já em estado gasoso é necessário um grande volume e pressão. As principais formas de armazenamentos são:

O reservatório de gás comprimido: atualmente a preocupação é minimizar o tamanho e maximizar o volume do hidrogênio armazenado, os fabricantes de cilindros estão tentando 
atingir as maiores pressões possíveis. Cilindros de alta pressão é comum armazenar hidrogênio com pressão de 3.600 psi "250 bar”, contudo novos desaines de cilindros tenham alcançado operar com 5000 psi (350 bar). Mas há estudos 23.500 psi (1620 bar) utilizando um cilindro de 10.000 psi (700 bar). (AMBIENTE BRASIL, 2013).

Figura 1. Reservatório de gás comprimido

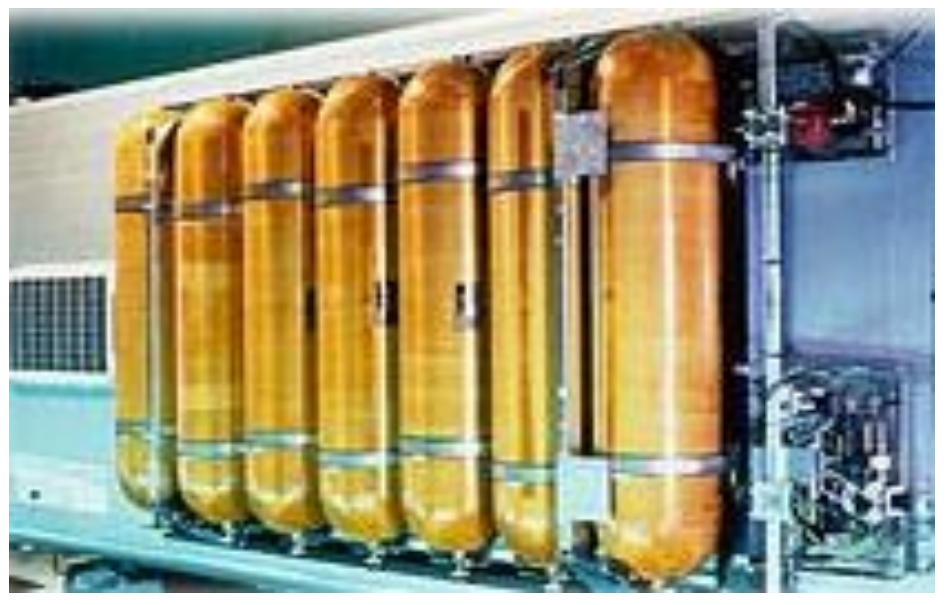

Fonte: Ambiente Brasil, 2013.

Reservatório de hidrogênio líquido: é necessário um modesto local para se armazenar grande quantidade de energia, o que de fato é considerado uma grande vantagem para a utilização em aviões e automóveis, assim os tanques conseguem ser leves de menor porte (SANTOS e SANTOS, 2001).

Hidretos metálicos: esse armazenamento acontece através da absorção do hidrogênio por metais em condições de alta pressão e temperatura controlada para gerar os hidretos metálicos, liberando o hidrogênio quando aquecido em baixa pressão e alta temperatura, porém esse método não é tão vantajoso, somente pode carregar o hidrogênio puro podendo ser contaminado o mesmo (AMBIENTE BRASIL, 2013).

Hidretos alcalinos: este método de armazenamento é recente, pois é uma variação do hidreto, o hidrogênio é petrificado podendo ser mantido coberto de maneira fácil para ser transportado. Já o sistema de armazenamento de microesferas é necessário pequenas esferas de vidro no qual o hidrogênio é forçado a entrar sob alta pressão (SANTOS e SANTOS, 2001).

\section{Volume do hidrogênio}

O hidrogênio - H ganha nas comparações de peso, justamente porque esse elemento é o mais leve da tabela periódica, pois o mesmo não tem os átomos de carbono, devido a esse 
fato satisfatório o $\mathrm{H}$ tem sido usado com frequência onde o quisto é peso, se tratando da energia liberada no período de reação do hidrogênio onde aproximadamente é 2,5 vezes do poder de combustão de um hidrocarboneto citando como exemplo o metano e a gasolina.

Mesmo o hidrogênio sendo o elemento mais leve da tabela periódica, ainda assim é mais denso em estado líquido referente a gasolina, Comparando-se com os tanques de gasolina, os sistemas de armazenamento de hidrogênio pode ser de 4 a 10 vezes maiores e pesados para uma quantidade equivalente de energia (SANTOS e SANTOS, 2011).

\section{Hidrogênio como fonte de combustivel}

O hidrogênio pode ser classificado como uma fonte de energia, porém é necessário encontrar soluções para produzi-lo, armazena-lo e transportá-lo. Nos dias atuais se busca soluções para solucionar os fatos citados e ainda para substituir os combustíveis fosseis pelos combustíveis renováveis já que os automóveis são vistos como um poluidor do meio em que vivemos.

No entanto o hidrogênio contém uma alta energia por unidade de peso relativamente com outro combustível, sua energia pode chegar aproximadamente a 2,5 vezes mais que o propano, gasolina e metano entre os demais, entanto isso na hora da combustão.

De acordo com Silva (2009), o hidrogênio promete ser essencial para a produção de energia nos próximos anos, essa revelação se deve as emissões de gases que necessita de intervenção por parte do homem. Neste sentido a vários projetos que utiliza o hidrogênio como combustível tais como: a Daimler-Chrysler possui o modelo de ônibus; a GM possui uma série de projetos em andamento; a Honda lançou o sedan Clarity, o qual está em fase de teste; a BMW lançou o primeiro sedan de luxo.

\section{Vantagens e desvantagens do hidrogênio como combustivel}

Para Zan (2010), as vantagens do hidrogênio são dadas devido a:

- Redução de emissão dos poluentes na atmosfera;

- Apresenta uma superior velocidade de combustão;

- Sua célula combustível é mais operativa do que o motor a combustão interna;

- Recurso ilimitado;

- Mesmo sendo obtido através de combustíveis emissores poluentes, pode diminuir a 50\% a emissão de dióxido de carbono e ainda torna-se combustível renovável. 
Já as desvantagens são: a inevitabilidade do uso de metais nobres como a platina, contém um elevado custo, o transporte do hidrogênio é visto como uma dificuldade e ainda a sua distribuição também (CELULA DE COMBUSTIVEL, 2013).

\section{Conclusões}

Atualmente é visível a produtividade sobre o hidrogênio - $\mathrm{H}$, sendo um fato positivo, porém ainda assim novos estudos devem ser fomentados em relação a utilização para combustível, como seu armazenamento e distribuição pelo Brasil. Os principais avanços se encontra na forma de armazenar e na utilização em forma de combustível surgindo como uma alternativa limpa e fácil de se produzir. Por fim este estudo permitiu compreender melhor o hidrogênio e seu desenvolvimento 


\section{Referências}

AMBIENTE

BRASIL,

Disponível

em:

<http://ambientes.ambientebrasil.com.br/energia/celula_combustivel/armazenamento_de_hidr ogenio.html>. Acesso em 29 de out de 2013.

CELULA DE COMBUSTIVEL, Disponível em <http://celulasdecombustivel.planetaclix.pt/vantagens.html>. Acesso em 29 de out de 2013.

MACEDO, M; U; CARVALHO, A. Química, Instituto Brasileiro de edições pedagógicas, 2006.

SANTOS, F; M; S; M. SANTOS, F; A; C; M. O Combustível "HIDROGÉNIO", Educação, ciência e tecnologia, 2001.

SILVA, G, M; SILVA, L, G, M; OIKNINE, L; DASSOLER, T, S; Produção Biotecnológica de Hidrogênio, Universidade Federal de Santa Catarina centro tecnológico departamento de engenharia química e alimentos, 2009.

ZAN, G, F, F; Hidrogênio, o combustível do futuro, Complexo educacional contemporâneo, 2010. 
Referências Bibliográficas

ABREU, V. M. N.; ABREU, P. G. Os desafios da ambiência sobre os sistemas de aves no Brasil.R. Bras. Zootec., v.40, p.1-14, 2001.

ALVES, S. P.; SILVA, I. J. O. \& PIEDADE, S. M. S. Avaliação do bem-estar de aves poedeiras comerciais: efeitos do sistema de criação e do ambiente bioclimático sobre o desempenho das aves e a qualidade de ovos. ESALQ/USP. Piracicaba - SP. 2007.

AMARAL, A.G., et al. Efeito do ambiente de produção sobre frangos de corte sexados criados em galpão comercial. Arq. Bras. Med. Vet. Zootec., v.63, n.3, p.649$658,2011$.

ARAÚJO, G. C.; BUENO, M. P. BUENO, V. P. et al. Cadeia produtiva da avicultura de corte: avaliação da apropriaçãode valor bruto nas transações econômicas dos agentes envolvidos. 2008.

BAÊTA, F.C.; SOUZA, C.F. Ambiência em edificações rurais, conforto animal. Viçosa, MG: Universidade Federal de Viçosa,1997.

CALIXTO, L. \& OLIVEIRA, L. T. D. A avicultura como atividade satisfatória para pequenos produtores com o sistema integrado de produção em um município do norte do Paraná. Universidade Estadual do Norte do Paraná. Cornélio Procópio. 2012.

CATALAN, A. A. S. \& MORAES, D. O. Manejo de aves poedeiras comerciais cria e recria. Universidade Federal de Pelotas - UFPel. Chapecó. 2010.

COBB. Manual de manejo de frangos de corte. 2008. Disponível em: <7TTP://wp.ufpel.edu.br/avicultura/files/2012/04/Cobb-Manual-Frango-Corte-BR.pdf> Acesso em: 20/05/2014.

DAMASCENO, F.A. et al. Mudanças climáticas e sua influência na produção avícola. PUBVET, Londrina, V. 4, N. 28, Ed. 133, Art. 901, 2010.

EMBRAPA. A avicultura no Brasil. 2013. Disponível em $<$ http://www.cnpsa.embrapa.br/cias/index.php?option=com_content\&view=article\&id= 13\&Itemid=15> Acesso em 20/05/2014.

FURLAN, R. L. Influencia da Temperatura na Produção de Frangos de Corte.VII Simpósio Brasil sul de avicultura - Chapecó, SC - Brasil. 2006.

GOMES, J.S. et al. Estresse Térmico na Avicultura. 2011. Disponível <http://fio.edu.br/cic/anais/2011_x_cic/PDF/Medicinaveterinaria/ESTRESSE\%20TER MICO\%20NA\%20AVICULTURA.pdf> Acesso em: 20/05/2014.

LANHAM, A. L.; GAMA, P. \& BRAZ, R. Arquitetura Bioclimática Perspectivas de inovação e futuro. Universidade Técnica de Lisboa, 2004.

MENEGALI, I., et al. Ambiente térmico e concentração de gases em instalações para frangos de corte no período de aquecimento. Revista Brasileira de Engenharia Agrícola e Ambiental. v.13, (Suplemento), p.984-990, 2009.

NÃÃS, I. de A. et al. Ambiência aérea em alojamento de frangos de corte: poeira e gases. Eng. Agríc. vol.27 no.2 Jaboticabal. 2007. 
NAVARINI, F.C. Níveis de Proteína Bruta e Balanço Eletrolítico para Frangos de Corte. 2009. Universidade Estadual do Oeste do Paraná, Marechal Cândido Rondon, 2009.

NOGUEIRA, A. C. L., et al. Coexistência de arranjos institucionais na avicultura de corte do estado de São Paulo. USP - Faculdade de Economia, Administração e Contabilidade. 2003.

OLIVEIRA, R. F. M. et al. Efeitos da temperatura e da umidade relativa sobre o desempenho e o rendimento de cortes nobres de frangos de corte de 1 a 49 dias de idade. R. Bras. Zootec., v.35, n.3, p.797-803, 2006.

PEREIRA, V. L. A. Qualidade de frangos de corte ao abate pela relação entre peso, doença de gumboro e algumas enfermidades associadas. Universidade Federal Fluminense. 2004.

ROCHA, J. S. R.; LARA, L. J. C. \& BAIÃ, N. C. Produção e bem-estar animal: Aspectos éticos e técnicos da produção intensiva de aves. Escola de Veterinária UFMG. 2008.

SINDIAVIPAR. Cooperativismo de resultados. Avicultura PR, ano V, n 28, 2012.

TAVARES, L. de P. \& RIBEIRO, K. C. de S. Desenvolvimento da avicultura de corte brasileira e perspectivas frente à influenza aviária. Organizações Rurais \& Agroindustriais, Lavras, v. 9, n. 1, p. 79-88, 2007.

UBA. União Brasileira de Avicultura. Protocolo de boas práticas de produção de ovos. São Paulo. Junho/2008. Disponível em: <http://www.avisite.com.br/legislacao/anexos/protocolo_de_boas_praticas_de_produca o_de_ovos.pdf> Acesso em: 20/05/2014.

UBA. União Brasileira de Avicultura. Relatório Anual. 2013. Disponível em <http://www.ubabef.com.br/publicacoes> Acesso em 20/05/2014.

UBABEF. Associação Brasileira de Proteína Animal. História da avicultura no Brasil. 2012.

Disponível

em:

<http://www.ubabef.com.br/a_avicultura_brasileira/historia_da_avicultura_no_brasil > Acesso em: 20/05/2014. 